\title{
PERCEPTIONS AND INTENTIONS OF ADOPTING THE INTERNET OF THINGS BY GENERATION Z
}

\author{
Silvana Costa Gonçalves ${ }^{1}$, Belem Barbosa ${ }^{2}$, Anabela Rocha ${ }^{3}$
}

\begin{abstract}
The Internet of Things (IoT) represents a new technological revolution expected to impact all aspects of our daily lives in the future. Generation $\mathrm{Z}$ is foreseen as playing a fundamental role in the adoption of this type of technology, namely because of their growing importance as a consumer segment, their global role in the society, and in particular their close relationship with technology. However, extant literature on the adoption of IoT disregarded this segment. This paper aims to fulfill this gap, by exploring their knowledge, perceptions, and intentions of adopting IoT. After considering the main contributions in the consumer behavior literature regarding IoT, a qualitative approach was adopted, and 7 semi-structured interviews were conducted with Portuguese consumers aged 18-22. Content analysis was performed following the recommendations by Bardin (1977). The results showed that although Generation $\mathrm{Z}$ is not familiar with the concept of the IoT, they expressed a strong desire to integrate IoT technology in their lives, being open to its adoption in all fields of application, including for personal use, at home, and for work. One of the conclusions is that in order to foster the IoT adoption by this Generation, the functional benefits (performance, price, comfort, and safety) should be emphasized, so that the main risks perceived are weakened, namely the financial, performance, and physical risks.
\end{abstract}

UDC Classification: 304, DOI: 10.12955/cbup.v7.1346

Keywords: Generation Z, Internet of Things, IoT Adoption, Perceived Risks, Perceived Benefits

\section{Introduction}

As organizations are increasingly developing new solutions based on the Internet of Things (IoT), their adoption by consumers is becoming an essential topic that deserves a lot of attention from practitioners, researchers, and public opinion alike. As age is widely accepted as a determining factor of technology adoption, it is crucial to focus research on the new generation of consumers - Generation Z (Gen Z). Still, extant literature has disregarded the perceptions and adoption of IoT by Gen Z. Indeed, the need of consumer behavior studies on IoT by Generation $\mathrm{Z}$ is notorious and urgent, considering their expected preponderant role in the future of IoT. Therefore, this paper aims to help fulfilling this gap by exploring the potential of the Generation $\mathrm{Z}$ segment of consumers to IoT products and services. The research objectives of this paper are (i) to identify Gen $\mathrm{Z}$ knowledge about the IoT, (ii) to analyze their perceived benefits and risks regarding IoT applications, and (iii) to explore their intentions of adopting IoT. This work presents relevant contributions for the literature about the Generation $\mathrm{Z}$ segment of consumers to IoT products and services providing strategic implications for the management and launching of IoT products and services targeting Generation Z.

\section{Literature Review}

The IoT represents an ecosystem of connected devices, computing mechanisms, and other items with ubiquitous intelligence that share data and information with each other, cooperating and creating countless benefits for its users (Luthra, Garg, Mangla, \& Singh Berwal, 2018). The application fields of IoT technologies are as numerous as they are diverse, covering all areas of our everyday life. It is estimated that by 2020 the number of connected devices will amount to 50 billion, changing business and life as we know (DuBravac \& Ratti, 2015; Kranz, 2016). Some of the most prominent domains for IoT applications are intelligent devices, industry 4.0, intelligent homes, wearables, independent living, intelligent cities, automotive, aerospace and aviation, health and medicine, pharmaceuticals, supply chain and logistics management, retail, agriculture and livestock, media and entertainment (Bandyopadhyay \& Sen, 2011; Ibarra-Esquer, González-Navarro, Flores-Rios, Burtseva, \& AstorgaVargas, 2017; Jindal, Jamar, \& Churi, 2018; Tiwary et al., 2018; Vermesan et al., 2013; Wortmann \& Flüchter, 2015).

Generation Z comprises individuals born after 1996 (Fromm \& Read, 2018; Lanier, 2017) these youngsters spent their lives surrounded by devices characteristic of the digital era, such as mobile phones, tablets, computers, and video game consoles. They live in permanent connection, in a world where there are no physical barriers and where the options are limitless (Prakash Yadav \& Rai, 2017). Consequently, Gen $\mathrm{Z}$ is characterized in extant literature by regular use of the Internet, total access to

\footnotetext{
${ }^{1}$ University of Aveiro, Portugal, silvana.goncalves@ua.pt

${ }^{2}$ University of Aveiro, Portugal, belem.barbosa@ua.pt

${ }^{3}$ University of Aveiro, Portugal, anabela.rocha@ua.pt
} 
information, and a great familiarity with communication and information technological advances that have occurred since the 1990s (Fromm \& Read, 2018; Geek, 2007; Koulopoulos \& Keldsen, 2014; Lanier, 2017; McCrindle \& Wolfinger, 2014; Prakash Yadav \& Rai, 2017; Prensky, 2001).

Technological innovations and globalization are therefore major influencers of the decision-making process of this generation. They think in 4D, where the visual and video elements are more and more preponderant and communication is increasingly done through shorter text messages (Fromm \& Read, 2018; Geek, 2007; Global Messaging, 2014; McCrindle \& Wolfinger, 2014). They are multi-taskers and often put more emphasis on speed than accuracy. They only know a wireless world, with hyperlinks, generated by the user, where they are always a few clicks away from any information. According to McCrindle and Wolfinger (2014) the world is an open book for Gen Z. Nevertheless, Geek (2007) argues that being perfectly familiar with technology does not make Gen $\mathrm{Z}$ members Internet experts, as they in fact are only familiar with a small part of the features offered by the Internet. Hence, the idea that they are ready for technological innovation should be avoided, as their adoption of new technological advances must be carefully explored.

One of the recommended approaches is to assess how IoT is perceived by Gen Z, both in terms of risks and benefits provided. The concept of perceived risk was introduced by Bauer (1960) and since then it has been frequently used for empirical and theoretical research. Perceived risk has been shown to explain consumer buying behavior, as consumers often intend to avoid risks and maximize the usefulness of the purchase (Cunningham, 1967; Jacoby \& Kaplan, 1972; Mitchell, 1999; Peter \& Ryan, 1976; Zikmund $\&$ Scott, 1974). Some IoT studies show that concerns about privacy and data security are one of the main risks perceived by consumers when considering adopting an IoT product/service (AlHogail, 2018; Hsu \& Lin, 2018; Jalali, Kaiser, Siegel, \& Madnick, 2017a; Woo, 2018). Overall, the literature presents perceived risk as comprising six dimensions (e.g., Jacoby \& Kaplan, 1972; Kaplan, Szybillo, \& Jacoby, 1974; Roselius, 1971): (i) financial risk (e.g., losing money); (ii) performance risk (e.g., the product/service will not meet the intended purpose); (iii) social risk (e.g., negative impact on what relevant others think of the consumer); (iv) physical risk (e.g., product/service causing damaging the individual's physical health); (v) psychological risk (e.g., negative impact on self-image); (vi) risk of loss of time (before, during, and after purchase, e.g., learning how to use the product/service).

While perceived risks act as deterrents to purchases of consumers, perceived benefits act as facilitators, so the greater the perceived benefits, the greater the likelihood of purchase (Kim, Ferrin, \& Rao, 2008). The theory of perceived benefits has often been applied to Internet-based research, including perceived benefits of e-commerce (Featherman \& Pavlou, 2003; Forsythe, Liu, Shannon, \& Gardner, 2006; Kim et al., 2008) applications of a connected lighting product (Jalali, Kaiser, Siegel, \& Madnick, 2017b), Internet banking (Lee, 2009), logistics (Kamarulzaman \& Nawi, 2009), and industry 4.0 (Dalenogare, Benitez, Ayala, \& Frank, 2018). Traditionally, the perceived benefits approach considers that consumers can be influenced by functional and non-functional (hedonic) motives, the former being related to functions such as convenience, variety and product quality and price, while later are related to the social and emotional needs of pleasant and interesting buying experiences (Forsythe et al., 2006).

\section{Method}

Based on the main contributions from extant literature, a semi-structured interview script was developed aiming to analyze Generation Z's perceptions and intentions of adopting the IoT. The study was conducted December 2018 and January 2019. A purposeful sample of adult Portuguese individuals born after 1996 (i.e., from 18 to 22 years of age), comprising both genders, different levels of education, and various professional occupations as described in table 1 . Considering the age span of this generation, and their lifecycle, most of Generation Z's individuals are still studying and have secondary education. These data are according to the characteristics of the general population (e.g., in Portugal, where the data collection took place). The total number of interviewees was seven, which was sufficient for data saturation to be reached, considering the exploratory nature of the study and again the short age span considered for this study. Interviews were recorded and transcribed, and a data analysis was carried out with the help of NVivo and following content analysis procedures proposed by Bardin (1977). Categories (e.g., knowledge, perceived risks, intentions) were initially defined based on the literature review. Two researchers were independently involved in the process, and the divergences in coding were carefully analyzed. 


\begin{tabular}{|}
$\mid$\begin{tabular}{|c|c|c|c|c|c|}
\hline \multicolumn{2}{|c|}{ Table 1: Interviewe's profile } \\
\hline $\mathbf{1}$ & Age & Gender & Level of education & Professional occupation & Interviews' duration (mm:ss) \\
\hline $\mathbf{1}$ & 20 & Male & Secondary education & Student & $23: 55$ \\
\hline $\mathbf{3}$ & 20 & Male & Secondary education & Student & $22: 19$ \\
\hline $\mathbf{4}$ & 22 & Female & Secondary education & Student & $22: 38$ \\
\hline $\mathbf{5}$ & 18 & Female & Secondary education & Kindergarten teacher & $26: 49$ \\
\hline $\mathbf{6}$ & 18 & Male & Secondary education & Student & $25: 54$ \\
\hline $\mathbf{7}$ & 22 & Male & Secondary education & Factory Worker & $18: 32$ \\
\hline
\end{tabular} Source: Author \\
\hline
\end{tabular}

\section{Results and Discussion}

Familiarity with the Internet and related technologies

It is widely acknowledged that Generation $\mathrm{Z}$ has been exposed to the Internet and its associated technologies more than any other generation before, making its members highly influenced by technology, which is ubiquitous in virtually every aspect of their lives. Undoubtedly, the interviewees revealed that they have a daily relationship with the Internet and associated technologies, using it for all aspects of their lives, particularly studying, searching information, and interacting with others. As shared by Interviewee 4:

"My relationship is like this (laughs), I can consider it a relation of almost dependence since I use it for almost everything on a daily basis, and even for work!"

Respondents corroborated the fact that the Internet has become ubiquitous in their lives through the various intelligent devices that have come to play a central role in their routines and become an extension of themselves (Global Messaging, 2014; Lynch, 2016; van Deursen, Bolle, Hegner, Kommers, \& Kommers, 2015). They develop much of their communication online, mentioning that the main sites and applications they use include Google, Instagram, Youtube, Facebook, Twiter and online newspapers.

\section{IoT Knowledge}

Despite being experienced with the online world and with technologies in general, Generation $\mathrm{Z}$ often limits the use of the Internet to simple tasks such as using social network sites and searching information of their interest. Thus, although they are experienced with the Internet, they only know a tiny part of this universe (Geek, 2007). Indeed, most respondents said they had never heard of the term Internet of Things. Only two interviewees were able to describe what IoT was, one of them because the topic is related to his area of study, and the other as a consequence of professional contacts. So, despite knowing and even using some IoT applications, some participants in this study were not aware of the concept of IoT in general. However, after listing its various applications (e.g., smartwatches and other wearables), all the interviewees mentioned being familiar with them, and immediately recognized their advantages for their daily life, namely in terms of comfort, task facilitators, and benefiting quality of life in general. As a counterpart, they mentioned that these applications can create addictions and it was mentioned the fear that IoT would replace some traditional tasks and cause unemployment. The only IoT application that was unanimously praised by the participants was the smartphone, which was portrayed as providing security to these young consumers.

Perceived Benefits

According to the theory of perceived benefits, consumer decision is driven by both functional motives (related to convenience, variety and quality of product and price) and nonfunctional reasons (related to emotions, as for instance pleasure) (Forsythe et al., 2006; Kim et al., 2008). In this study the interviewees agreed that IoT has perceived functional benefits, mainly performance, best prices, comfort, and safety. On the other hand, the perceived nonfunctional benefits appear to be of no relevance to this generation.

"Not so much. I think it's not much around. I do not think it generates great emotions. I mean ... I do not think so, no!" (Interviewee 2)

\section{Perceived Risks}

For the participants in this study, financial, performance, and physical risks are preponderant variables when thinking about the adoption of IoT technology. This is consistent to indications that this is a 
cautious generation trying to distance itself from risky behaviors and seeking to make wise choices (Scott, 2016). In the case of physical risk, the interviewees associated IoT with potential addictions, as for instance Interviewee 5 mentioned: "people end up getting too addicted and stay in a world apart."

Also mentioned was the risk of data loss, although views on the topic varied. While some interviewees worried about their privacy being totally compromised with IoT adoption, others devalued it, and affirmed that they end up forgetting about this risk. Some did not associate physical risk with privacy loss:

"Physical integrity I do not think so, there is no such great threat, but privacy is totally compromised." (Interviewee 2)

"I always try to forget it, I do not worry that much about [privacy risks]." (Interviewee 3)

The social risk and risk of loss of time were considered irrelevant by the interviewees and as for the psychological risk the opinions were divided and in fact the majority of respondents considered that the social risk is not considerable.

Hence, this study provides empirical evidence that Generation $\mathrm{Z}$ members seek transparent, authentic, and secure interactions. Therefore, it is crucial that marketers find a balance between privacy and personalization in order to interact with this generation online (Woo, 2018), and to guide the offers of technology-related products and services, such as IoT.

Intention to adopt IoT technologies

For Generation Z, the internet is an integral part of their daily lives (Swanepoel, Lye, \& Rugimbana, 2009), as these youngsters have never known a non-digital world (Woo, 2018). So, it is not surprising that all respondents mentioned that they intend to buy and use IoT products and services, portraying themselves as adopters of all type of IoT applications. Moreover, they considered that the IoT expected development and the increase of this type of applications will foment their willingness to integrate IoT in their lives.

According to the literature, Generation $\mathrm{Z}$ is attracted to security and pragmatism, so the reasons that are expected make them adopt more IoT applications are convenience, safety, comfort, professional necessity, speed up tasks, to innovate, and to communicate more easily (Scott, 2016). In addition, the price, influence of family and friends, and their experience with IoT technology will be determining factors in the adoption of certain IoT applications by generation Z, as explained for instance by Interviewee 4:

"(...) smart homes, maybe not for now... maybe the price is still too high for me to get these kinds of products."

\section{Conclusion}

One of the most notorious results provided by this study is that Generation $\mathrm{Z}$ consumers might not be familiar with concept of the Internet of Things. In fact, although they use and are aware of most of its domains and applications, they often started by saying that they had never come across either the term "Internet of Things" or its acronym "IoT". Clearly, this fact posits one additional challenge to professionals and brands working in this sector, being necessary to educate consumers, including of this generation, about what the Internet of Things is, and to inform them about the various applications that exist and their advantages. Generation $\mathrm{Z}$ uses IoT, mainly through smartphones, which it uses to interact with its friends through social networks, such as Facebook, Snapchat and Twitter. Part of the Generation $\mathrm{Z}$ elements are also college students, who tend to resort to platforms, apps, music and video streaming services. In addition, there are also several software applications designed to assist this generation throughout their academic career. In fact, the school environment is increasingly connected (Matthews, 2018). Therefore, recommendations to make them more familiar with the concept include communication through social network sites and lectures in the school environment.

Generally, this generation has a strong desire to adopt IoT technology. Indeed, participants did not exclude the adoption of IoT in any domain. However, in order to reduce perceived risks and consequently to foster the adoption of IoT, it is crucial to enhance consumer confidence and demonstrate the potential benefits provided, since the perceived benefits and perceived risks ratio vary inversely (AlHogail, 2018; Hsu \& Lin, 2018; Jalali et al., 2017a; Woo, 2018). According to this study, the main advantages that should be emphasized when communicating a specific IoT product/service are 
convenience, safety, comfort, and innovation. In addition, it is crucial to pay attention to the price and carefully explain the value provided, because in general IoT prices are perceived as too high which will certainly present several elements of this generation to consider several domains of IoT product/service. According to our results, the main IoT benefits perceived by this generation are functional, so it is important that when communicating the advantages of a certain IoT product/service, the functional benefits are emphasized, namely the main functional benefits mentioned by the interviewees which were performance, comfort, and safety. This generation is cautious about distancing itself from risky behaviors and seeks to make wise choices. Thus, when communicating a certain IoT product/service, it is also necessary to demonstrate its functional features, and hence try to reduce the perception of financial, performance, and physical risks, which were the most stressed by the participants in this study. Therefore, this study offers interesting implications for IoT products and services brands and companies that intend to target Generation Z's consumers. As for scholars, this study also demonstrates that this is a topic deserving further research, which could both tackle IoT as a concept that encompasses a great diversity of applications, and to directly explore particular forms of IoT, such as wearables or home appliances. Suggestions for future research include conducting exploratory research with different populations, making international comparisons of consumer behavior regarding IoT, and to compare different generations. Moreover, other methodological approaches, both qualitative and quantitative should also be considered, and the consideration of other variables (e.g., predisposition to innovation, digital literacy) would be of great value to further understand IoT adoption by Generation Z.

\section{References}

Al Hogail, A. (2018). Improving IoT technology adoption through improving consumer trust. Technologies, 6(3), 64. https://doi.org/10.3390/technologies6030064

Bandyopadhyay, D., \& Sen, J. (2011). Internet of things: Applications and challenges in technology and standardization. Wireless Personal Communications, 58(1), 49-69. https://doi.org/10.1007/s11277-011-0288-5

Bardin, L. (1977). Análise de conteúdo. Lisboa: Edições 70. Retrieved from www.edicoes70.pt

Bauer, R. A. (1960). Consumer behavior as risk taking. In R. S. Hancock (Ed.), Dynamic Marketing for a Changing World: Proceedings of the 43rd National Conference of the American Marketing Association (pp. 389-398). Chicago: American Marketing Assocation.

Cunningham, S. M. (1967). The major dimensions of perceived risk. In Donald F. Cox. (Ed.), Risk taking and information handling in consumer behavior (pp. 82-111). Boston: Harvard University. Retrieved from https://www.econbiz.de/

Dalenogare, L. S., Benitez, G. B., Ayala, N. F., \& Frank, A. G. (2018). The expected contribution of Industry 4.0 technologies for industrial performance. International Journal of Production Economics, 204, 383-394. https://doi.org/10.1016/j.ijpe.2018.08.019

DuBravac, S., \& Ratti, C. (2015). The internet of things: Evolution or revolution? (No. Part1 series, 1). Retrieved from www.aig.com/innovativetech

Featherman, M. S., \& Pavlou, P. A. (2003). Predicting e-services adoption: a perceived risk facets perspective. International Journal of Human-Computer Studies, 59(4), 451-474. https://doi.org/10.1016/S1071-5819(03)00111-3

Forsythe, S., Liu, C., Shannon, D., \& Gardner, L. C. (2006). Development of a scale to measure the perceived benefits and risks of online shopping. Journal of Interactive Marketing, 20(2), 55-75. https://doi.org/10.1002/DIR.20061

Fromm, J., \& Read, A. (2018). Marketing to Gen Z: The rules for reaching this vast--and very different--generation of influencers. Nova York: American Management Association. Retrieved from https://books.google.pt

Geek, C. (2007). The Generation Z connection: Teaching information literacy to the newest net generation. In E. Rosenfeld \& D. V. Loertscher (Eds.), Toward a 21st-century school library media program (pp. 235-241). United Kingdom: Scarecrow Press. Retrieved from https://books.google.pt

Global Messaging. (2014). Beyond facebook marketing to Generation Z. Digital Marketing Magazine. Retrieved from http://digitalmarketingmagazine.co.uk

Hsu, C.-L., \& Lin, J. C.-C. (2018). Exploring factors affecting the adoption of internet of things services. Journal of Computer Information Systems, 58(1), 49-57. https://doi.org/10.1080/08874417.2016.1186524

Ibarra-Esquer, J., González-Navarro, F., Flores-Rios, B., Burtseva, L., \& Astorga-Vargas, M. (2017). Tracking the evolution of the internet of things concept across different application domains. Sensors, 17(6), 1379.

https://doi.org/10.3390/s17061379

Jacoby, J., \& Kaplan, L. B. (1972). The components of perceived risk. In M. Venkatesan (Ed.), SV - Proceedings of the Third Annual Conference of the Association for Consumer Research, (pp. 382-393). Chicago, IL: Association for Consumer Research. Retrieved from http://acrwebsite.org

Jalali, M. S., Kaiser, J. P., Siegel, M., \& Madnick, S. (2017a). The internet of things (IoT) promises new benefits and risks: A systematic analysis of adoption dynamics of IoT products. SSRN Electronic Journal. https://doi.org/10.2139/ssrn.3022111

Jalali, M. S., Kaiser, J. P., Siegel, M., \& Madnick, S. (2017b). The Internet of Things (IoT) Promises New Benefits And 
Risks: A Systematic Analysis of Adoption Dynamics of IoT Products. SSRN Electronic Journal. https://doi.org/10.2139/ssrn.3022111

Jindal, F., Jamar, R., \& Churi, P. (2018). Future and challenges of internet of things. International Journal of Computer Science and Information Technology, 10(2), 13-25. https://doi.org/10.5121/ijcsit.2018.10202

Kamarulzaman, N., \& Nawi, N. M. (2009). The use of internet applications in managing logistics activities among palm oil industry participants. International Journal of Economics and Management, 3(2), 262-277.

Kaplan, L. B., Szybillo, G. J., \& Jacoby, J. (1974). Components of perceived risk in product purchase: A cross-validation. Journal of Applied Psychology, 59(3), 287-291. https://doi.org/10.1037/h0036657

Kim, D. J., Ferrin, D. L., \& Rao, H. R. (2008). A trust-based consumer decision-making model in electronic commerce: The role of trust, perceived risk, and their antecedents. Decision Support Systems, 44(2), 544-564 https://doi.org/10.1016/j.dss.2007.07.001

Koulopoulos, T. M., \& Keldsen, D. (2014). The Gen Z effect : the six forces shaping the future of business. Brookline: Bibliomotion, Inc. Retrieved from https://books.google.pt

Kranz, M. (2016). Building the Internet of things : implement new business models, disrupt competitors, and transform your industry. New Jersey: John Wiley \& Sons. Retrieved from https://books.google.pt/

Lanier, K. (2017). 5 things HR professionals need to know about Generation Z. Strategic HR Review, 16(6), $288-290$. https://doi.org/10.1108/SHR-08-2017-0051

Lee, M.-C. (2009). Factors influencing the adoption of internet banking: An integration of TAM and TPB with perceived risk and perceived benefit. Electronic Commerce Research and Applications, 8(3), 130-141. https://doi.org/10.1016/J.ELERAP.2008.11.006

Luthra, S., Garg, D., Mangla, S. K., \& Singh Berwal, Y. P. (2018). Analyzing challenges to Internet of Things (IoT) adoption and diffusion: An Indian context. Procedia Computer Science, 125, 733-739. https://doi.org/10.1016/J.PROCS.2017.12.094

Lynch, M. (2016). Leave my iPhone alone: why our smartphones are extensions of ourselves. The Guardian. Retrieved from https://www.theguardian.com

Matthews, K. (2018). How are different generations using IoT? [Web log post]. Retrieved June 26, 2018, from https://www.iotforall.com

McCrindle, M., \& Wolfinger, E. (2014). The ABC of XYZ : understanding the global generations (3rd ed.). Sydney: McCrindle Research Pty Ltd. Retrieved from https://s3.amazonaws.com/

Mitchell, V. (1999). Consumer perceived risk: conceptualisations and models. European Journal of Marketing, 33(1/2), 163195. https://doi.org/10.1108/03090569910249229

Peter, J. P., \& Ryan, M. J. (1976). An investigation of perceived risk at the brand level. Journal of Marketing Research, 13(2), 184-188. https://doi.org/10.2307/3150856

Prakash Yadav, G., \& Rai, J. (2017). The Generation Z and their social media usage: A review and a research outline. Global Journal of Enterprise Information System, 9(2), 110-116. https://doi.org/10.18311/gjeis/2017/15748

Prensky, M. (2001). Digital natives, digital immigrants. From On the Horizon, 9(5), 1-6.

https://doi.org/https://doi.org/10.1108/10748120110424816

Roselius, T. (1971). Consumer rankings of risk reduction methods. Journal of Marketing, 35(1), 56-61.

https://doi.org/10.2307/1250565

Scott, R. (2016, November 28). Get ready for generation Z. Forbes. Retrieved from https://www.forbes.com

Swanepoel, C., Lye, A., \& Rugimbana, R. (2009). Virally inspired: A review of the theory of viral stealth marketing. Australasian Marketing Journal (AMJ), 17(1), 9-15. https://doi.org/10.1016/j.ausmj.2009.01.005

Tiwary, A., Chidar, A., Shrivastava, M., Mahato, M., Chandrol, M. K., \& Tripathi, M. (2018). Internet of Things (IoT): Research, architectures and applications. International Journal on Future Revolution in Computer Science \& Communication Engineering (IJFRSCE), 4(3), 23 - 27. Retrieved from http://www.ijfrcsce.org

van Deursen, A. J. A. M., Bolle, C. L., Hegner, S. M., Kommers, P. A. M., \& Kommers, P. A. M. (2015). Modeling habitual and addictive smartphone behavior. Computers in Human Behavior, 45, 411-420. https://doi.org/10.1016/j.chb.2014.12.039

Vermesan, O., Friess, P., Guillemin, P., Sundmaeker, H., Eisenhauer, M., Moessner, K., .. Cousing, P. (2013). Internet of things strategic research and innovation agenda. In P. F. Ovidiu Vermesan (Ed.), Internet of Things - Converging Technologies for Smart Environments and Integrated Ecossystems (pp. 7-151). Aalborg,Denmark: River Publisher. Retrieved from https://s3.amazonaws.com

Woo, A. (2018, July 23). Time to wake up to the next consumer powerhouse: Gen Z. Forbes. Retrieved from https://www.forbes.com/

Wortmann, F., \& Flüchter, K. (2015). Internet of Things. Business \& Information Systems Engineering, 57(3), $221-224$. https://doi.org/10.1007/s12599-015-0383-3

Zikmund, W. G., \& Scott, J. E. (1974). A multivariate analysis of perceived risk self-confidence and information sources. In S. Ward, P. Wright, \& A. Abor (Eds.), NA - Advances in Consumer Research (Vol. 1, pp. 406-416). Michigan: Association for Consumer Research. Retrieved from http://www.acrwebsite.org/ 